of said complications is increasing may be true, but this again had nothing to do with the integrity of previous estimates made in a good faith effort to study results. I hope this clarifies any question in the readers' minds as to the intention of my statements regarding this issue.

Daniel J. DiBardino, MD

Chief Resident in Cardiac Surgery Brigham and Woman's Hospital and Children's Hospital Boston Program Boston, Mass

\begin{abstract}
References
1. DiBardino DJ, McElhinney DB, Kaza AK, Mayer JA. Analysis of the U.S. Food and Drug Administration MAUDE Database for adverse events involving transcatheter septal occluder devices and comparison to Society of Thoracic Surgeons Congenital Cardiac Surgery database. J Thorac Cardiovasc Surg. 2009;137:1334-41.

2. Amin Z, Hijazi ZM, Bass JL, Cheatham JP, Hellenbrand WE, Kleinman CS. Erosion of Amplatzer septal occluder device after closure of secundum atrial septal defects: review of registry of complications and recommendations to minimize future risk. Catheter Cardiovasc Interv. 2004;63:496-502.
\end{abstract}

doi:10.1016/j.jtcvs.2009.06.012

\section{MICHAEL E. DEBAKEY}

The obituary of Dr DeBakey was very interesting. ${ }^{1}$ One of Dr DeBakey's pioneering efforts does need special emphasis. By using autologous saphenous vein(s), on November 23, 1964, ${ }^{2}$ DeBakey performed the first human coronary artery bypass graft surgery to the left anterior descending coronary artery in an asymptomatic patient after myocardial infarction.

Shahbudin H. Rahimtoola, MB, FRCP, DSC (Hon) LAC+USC Medical Center Cardiology Los Angeles, Calif

\section{References}

1. Frazier OH, Michael E. DeBakey, 1908-2008. J Thorac Cardiovasc Surg. 2008;136:809-11.

2. Garrett EH, Dennis EW, DeBakey ME. Aortocoronary bypass with saphenous vein grafts: seven-year follow-up. JAMA. 1973;223:792-4.

doi:10.1016/j.jtcvs.2009.05.022

\section{PULMONARY ARTERIAL HYPERTENSION AND CONGENITAL HEART DISEASE: TARGETED THERAPIES AND OPERABILITY \\ To the Editor:}

We read with great interest the case report of Hoetzenecker and colleagues ${ }^{1}$ of a patient with severe pulmonary arterial hypertension associated with an atrial septal defect and the beneficial effect of bosentan, which allowed for closure of the defect. This is a very interesting topic that raises a lot of controversies in the field of pulmonary arterial hypertension associated with congenital heart disease. ${ }^{2}$

I would like to comment on the hemodynamic data presented in Table 1 . Total pulmonary resistance at baseline is calculated at 460 dynes $\cdot \mathrm{s}^{-1} \cdot \mathrm{cm}^{-5}$, but pulmonary vascular resistance, taking the mean left atrial pressure in the calculation, which is commonly done in congenital heart disease, would give a value of 311 dynes . $\mathrm{s}^{-1} \cdot \mathrm{cm}^{-5}$ or 3.9 Wood units, which is very close to a value of 3 Wood units considered as totally safe for surgical repair. If we calculate the ratio of pulmonary to systemic blood flow $(\mathrm{Qp} /$ Qs), we have a value of 2.7 , which is also considered a value that allows for repair.

Moreover, when we look at the data during the nitric oxide testing, these values reach a pulmonary vascular resistance of 1.78 Wood units or 142 dynes . $\mathrm{s}^{-1} \cdot \mathrm{cm}^{-5}$, the Qp/Qs is 3.25 , and the pulmonary arterial saturation reaches $84.5 \%$. All these values are consistent with a reactive pulmonary vascular bed and are values that will clearly allow closure of the shunt for a congenital cardiologist. ${ }^{3,4}$ It would be of interest also to report the ratio of pulmonary over systemic vascular resistance, as a ratio $<0.33$ indicates good prognosis after closure of the shunt. ${ }^{4}$

Maybe the authors used the definition of reactivity used for other forms of pulmonary arterial hypertension, al- lowing for the use of calcium channel blockers, but this may not be applied for the evaluation of operability in patients with congenital heart disease. Why did the authors think that this particular patient required bosentan treatment based on these measurements? If we look at the data after treatment and just before repair, the hemodynamic does not look much better than with nitric oxide, as the pulmonary vascular resistance is 2.6 Wood units or 205 dynes $\cdot \mathrm{s}^{-1} \cdot \mathrm{cm}^{-5}$ and Qp/Qs is 2.24 . Why was the patient considered operable with these values but not before? If this is based only on mPAP, I would suggest the authors should discuss the fact that mLAP also had a significant decrease.

Finally, if we analyze the measurement 8 months after repair, the pulmonary vascular resistance is 4.2 and the mean pulmonary arterial pressure is $35 \mathrm{~mm} \mathrm{Hg}$ - still not normal. We clearly hope that these values will remain at these levels and not rise again in the coming month, as the outcome, at least in pediatric patients with recurrent pulmonary hypertension after repair, is dismal, as shown recently by Haworth and colleagues. ${ }^{5}$

Maurice Beghetti, $M D$

Cecile Tissot, $M D$

Pediatric Cardiology Unit Department of the Child and

Adolescent

Children's University Hospital of

Geneva

Geneva, Switzerland

\section{References}

1. Hoetzenecker K, Ankersmit HJ, Bonderman D, et al. Atrial septal defect repair after a 10-month treatment with bosentan in a patient with severe pulmonary arterial hypertension: a case report. $J$ Thorac Cardiovasc Surg. 2009;137:760-1.

2. Dimopoulos K, Peset A, Gatzoulis MA. Evaluating operability in adults with congenital heart disease and the role of pretreatment with targeted pulmonary arterial hypertension therapy. Int J Cardiol. 2008;129:163-71

3. Berner M, Beghetti M, Spahr-Schopfer I, Oberhansli I, Friedli B. Inhaled nitric oxide to test the vasodilator capacity of the pulmonary vascular bed in children with long-standing pulmonary 